\title{
The differential diagnosis of suspected stroke: a systematic review
}

\author{
${ }^{1}$ LM Gibson, ${ }^{2} \mathrm{~W}$ Whiteley \\ ${ }^{1}$ ST1 in Clinical Radiology, Department of Clinical Radiology; ${ }^{2}$ MRC Clinician Scientist and Honorary Consultant Neurologist, Division of \\ Clinical Neurosciences, Western General Hospital, Edinburgh, UK
}

\section{ABSTRACT}

Background: We aimed to determine the proportion of patients who had suffered a stroke and compare this to those patients with suspected stroke, and the range of differential diagnosis for suspected stroke.

Methods: We searched for prospective studies of suspected stroke in electronic databases and our personal files. We undertook a meta-analysis of these studies, aimed at determining the proportions of patients with confirmed stroke in different settings.

Results: We identified 29 studies involving 8,839 patients: I 3 studies were from emergency departments, five from stroke units or transient ischaemic attack (TIA) clinics, three from primary care, three from ambulance services and five were unspecified.About three-quarters (74\% [95\% confidence interval (Cl): 66 to 83\%]) of patients had a diagnosis of stroke, though there was significant heterogeneity in this estimate. The five most frequent non-stroke diagnoses were seizure, syncope, sepsis, migraine and brain tumours.

Conclusion: Patients who had not had a stroke accounted for a significant proportion of people referred to stroke services. Expertise in the differential diagnoses of stroke is needed in order to manage the patients at the point of referral.

KEYWORDS Stroke, diagnosis, systematic review, epidemiology

DECLARATION OF INTERESTS Dr Whiteley reports grants from MRC Clinician Scientist Fellowship during the conduct of the study.
Correspondence to LM Gibson, Department of Clinical Radiology, Western General Hospital, Crewe Road South, Edinburgh EH4 2XU, UK tel. +44 (0) I3I 537 I089 e-mail lornagibson I@nhs.net

\section{INTRODUCTION}

Patients with suspected stroke present to primary care, ambulance services and emergency departments. The care setting, patient characteristics or diagnostic methods used can all influence an assessment of suspected stroke. The proportion of people identified with suspected stroke is important, as the diagnostic performance of clinical, radiological and other tests depends on the pre-test probability of stroke. ${ }^{\mathrm{RI}} \mathrm{We}$ therefore aimed to determine the proportion of suspected stroke patients who had a stroke, those study features that had an important influence on this proportion, and the most common differential diagnoses of patients with suspected stroke who had not had one.

\section{METHODS}

Using a detailed and specific list of criteria (available online), we searched our files and the biomedical database Ovid Medline for records up to 30 May 2012 for prospective studies of suspected stroke patients. We did not routinely contact study authors, search the 'grey' literature, or include studies in non-European languages due to limited resources. We included published studies that: (i) recruited patients with suspected stroke only, (ii) were prospective, and (iii) reported the proportion of patients with a final diagnosis of stroke or transient ischaemic attack (TIA). Our reference standard for the diagnosis of stroke, was 'clinical assessment by a trained observer and brain imaging.'

We extracted data on country, diagnostic methods, patient demographics, average stroke severity and final diagnosis. We recorded whether stroke was suspected by a primary care doctor, an ambulance paramedic, or a member of emergency department staff in order to characterise the referral source. We recorded the number of patients who received a final diagnosis of ischaemic stroke, TIA, haemorrhagic stroke and all stroke. We included patients with subarachnoid haemorrhage in our definition of 'haemorrhagic stroke', though they were rare. Finally, we extracted all available data on final diagnoses other than stroke. We defined non-stroke diagnoses as: 'syncope' (syncope, presyncope, cardiovascular collapse, postural hypotension and dehydration); 'vertigo' (labyrinthine disorders and vestibulopathies); 'myelopathies' (spinal stenosis, cervical myelopathy, demyelination, spinal trauma); 'drugs and alcohol'; 'metabolic' (toxic/metabolic, 
encephalopathy, hypoglycaemia, hyponatraemia and metabolic coma); 'functional disorders' (anxiety, hyperventilation and depression); 'benign headache disorders' (migraine and tension headache) and 'sepsis' (including delirium). If any of the above data were not available from the study report, they were classed as not reported.

We performed a random effects meta-analysis of the proportion of patients with stroke or TIA seen in each healthcare setting. We used the $\mathrm{I}^{2}$ statistic to estimate the heterogeneity of individual studies contributing to the pooled estimate. The $\mathrm{I}^{2}$ statistic ranges from $0 \%$ to $100 \%$, with $25 \%$ corresponding to low statistical heterogeneity, $50 \%$ to moderate and $75 \%$ to high. We calculated the pooled proportion as the back transform of the weighted mean of the transformed proportions, using DerSimonianLaird weights in a random effects model, and reported $95 \%$ confidence interval $(\mathrm{Cl})$. We used data analysis and statistical software for the analysis.

\section{RESULTS}

Our search strategy retrieved 3,075 papers. We identified 25 relevant studies (listed in the reference section) of 29 cohorts with a total of 8,839 suspected stroke patients. Emergency department staff suspected stroke in 13 cohorts, ${ }^{1-13}$ primary care physicians in four, ${ }^{2,4,7,14}$ stroke units/TIA clinics in four, ${ }^{15-18}$ paramedics in three ${ }^{4,19-20}$ and other settings in five. ${ }^{21-25}$ Sixteen studies were conducted in European countries, five in the USA, two in Canada and one each in Malawi and Australia. Of the 5,977 patients diagnosed with stroke, 4,666 (78.1\%) had an ischaemic stroke, 668 (11.2\%) had a haemorrhagic stroke, and for the remaining 643 (10.8\%) no stroke type was specified.

The pooled proportion of suspected stroke patients with stroke was $74 \%$ (95\% Cl: 66 to 83\%) with high between-study heterogeneity $\left(I^{2}=99 \%\right)$ in the summary estimate. There was no good statistical evidence that the source of referral made a difference to the proportion of suspected stroke patients with an eventual diagnosis of stroke or TIA (Figure I). There was significant heterogeneity in the estimates of the proportions of patients with suspected stroke in each setting, though the proportion of patients with stroke in a stroke unit was higher than in other settings.

Seventeen of the 25 relevant studies investigated aspects of the diagnosis of stroke; ${ }^{1,2,4-15,18-20}$ five intended to determine the epidemiology of stroke mimics ${ }^{3,16,22,24,25}$ (including two looking at the differential diagnosis of stroke). ${ }^{3,24}$ The remaining three investigated thrombolysis rates, ${ }^{17}$ time to admission ${ }^{21}$ and an uncommon presentation of stroke. ${ }^{23}$
Twenty of the 25 studies reported the differential diagnoses of stroke. . $^{2-7,9-12,14-18,20-22,24,25}$ The 20 most common are given in Table I; they account for the final diagnoses of $96 \%$ of patients with suspected stroke who did not have either stroke or TIA.

\section{TABLE I The 20 most common differential diagnoses of} suspected stroke

\begin{tabular}{|l|c|c|}
\hline $\begin{array}{l}\text { Differential } \\
\text { diagnosis }\end{array}$ & $\mathbf{n}$ & $\begin{array}{c}\text { As a percentage of } \\
\text { patients reported } \\
\text { to have a final } \\
\text { diagnosis other } \\
\text { than stroke or } \\
\text { transient ischaemic } \\
\text { attack (n=8 I3) }\end{array}$ \\
\hline Seizure & 159 & 19.6 \\
\hline Syncope & 99 & 12.2 \\
\hline Sepsis & 78 & 9.6 \\
\hline $\begin{array}{l}\text { Benign headache } \\
\text { disorder }\end{array}$ & 73 & 9.0 \\
\hline Brain tumour & 67 & 8.2 \\
\hline Functional & 60 & 7.4 \\
\hline Metabolic & 50 & 6.2 \\
\hline Not specified & 41 & 5.0 \\
\hline Neuropathy & 37 & 4.6 \\
\hline Vertigo & 26 & 3.2 \\
\hline Dementia & 19 & 2.3 \\
\hline $\begin{array}{l}\text { Extra- or subdural } \\
\text { haemorrhage }\end{array}$ & 15 & 1.8 \\
\hline Drugs and alcohol & 13 & 1.0 \\
\hline $\begin{array}{l}\text { Transient global } \\
\text { amnesia }\end{array}$ & 11 & 0.9 \\
\hline Myelopathy & 8 & 0.7 \\
\hline Hypertension related & 7 & 0.5 \\
\hline Parkinson's disease & 6 & 0.5 \\
\hline Encephalopathy & 4 & 1.4 \\
\hline Trauma & 4 & 3 \\
\hline Invasive procedure & 3 & \\
\hline & & \\
\hline
\end{tabular}

All of the relevant studies that we reviewed used imaging to confirm stroke. In the 12 studies $2,3,9,10,12-15,17,18,24,25$ that reported the proportion of patients with suspected stroke using imaging there was variation in the number of patients who had undergone a computed tomography (CT) scan (from $29.7[244 / 821]^{15}$ to $100 \%$ [80/80, $191 / 191]^{10,12,13,17,23}$ and those who had magnetic resonance (MR) brain imaging $\left(3.5 \%[29 / 835]^{25}\right.$ to $\left.100 \%[191 / 191]^{10}\right)$. Limited data were available on stroke severity from nine studies, ${ }^{1,3,10,12-14,18,21,22}$ of which eight reported mean or median National Institutes of Health Stroke Scale (NIHSS) scores and one reported median Barthel scores; ${ }^{21}$ only three gave minimum and maximum scores. ${ }^{1,18,21}$ Thirteen studies (52.0\%) reported time from symptom onset to assessment: the median time was less 


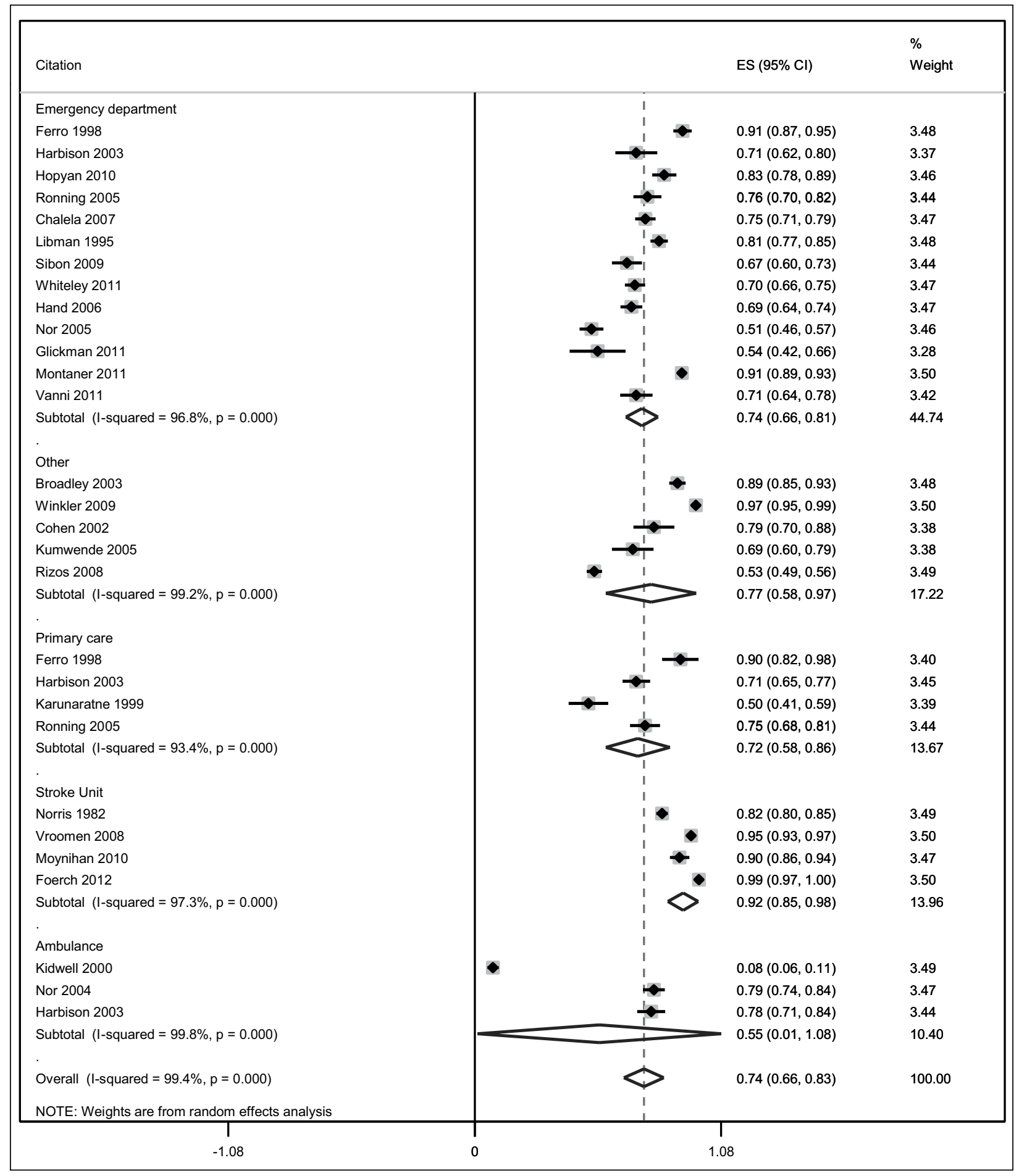

FIGURE I The proportion of suspected stroke patients with an eventual diagnosis of stroke or transient ischaemic attack (TIA), from ambulance, primary care, emergency department and other referral sources. The size of each square is proportional to the weight given to the study in the summary estimates, and the 12 statistic is given as an estimate of heterogeneity in the summary estimates. 
than six hours in seven studies, ${ }^{6,9-11,17-19}$ six to 24 hours in five ${ }^{1,2,13,20,21}$ and over 24 hours in one. ${ }^{14}$ Seventeen studies reported the average (mean or median) age of study participants: less than 65-years-old in two studies and 65 or over in 15 studies.

The country in which the study took place, the proportion of patients who had MR scans, or the timing of the assessment did not account for the significant between-study heterogeneity in the proportion of the suspected stroke patients with a diagnosis of stroke. Although the proportion of patients with stroke differed between studies where the mean age of patients was under or over 65 this result was heavily influenced by one study with an unusually low proportion of patients with stroke.

\section{DISCUSSION}

We found that about three-quarters of patients with suspected stroke had a final diagnosis of stroke, though there was considerable variation between studies that was not explained either by aspects of the study design (country, referral source) or the average characteristics of the patients (age, severity, or delay to assessment). The common differential diagnoses of stroke included neurological and non-neurological disorders.

We found only limited data on time to patient assessment, mean patient age, use of CT or MRI scans, stroke severity, and history of prior stroke; if we had complete data, our conclusions may have changed.

\section{REFERENCES (R)}

I Feinstein AR. Misguided efforts and future challenges for research on 'diagnostic tests'. J Epidemiol Community Health 2002; 56:330-2. http://dx.doi.org/I0.I I36/jech.56.5.330

2 Goldstein LB, Simel DL. Is this patient having a stroke? JAMA 2005; 293:239I-402. http://dx.doi.org/I0.100I/jama.293.19.239I

\section{STUDY REFERENCES}

I Chalela JA, Kidwell CS, Nentwich LM et al. Magnetic resonance imaging and computed tomography in emergency assessment of patients with suspected acute stroke: a prospective comparison. Lancet 2007; 369:293-8. http://dx.doi.org/I0.I0I6/S0I406736(07)60I5I-2

2 Ferro JM, Pinto AN, Falcao I et al. Diagnosis of stroke by the nonneurologist. A validation study. Stroke 1998; 29:। I06-9. http:// dx.doi.org/I0.II6I/0I.STR.29.6.II06

3 Hand PJ, Kwan J, Lindley RI et al. Distinguishing between stroke and mimic at the bedside: the brain attack study. Stroke 2006; 37:769-75. http://dx.doi.org/I0.I I6I/0I.STR.000020404I.I3466.4c

4 Harbison J, Hossain O, Jenkinson D et al. Diagnostic accuracy of stroke referrals from primary care, emergency room physicians, and ambulance staff using the face arm speech test. Stroke 2003; 34:7 I-6. http://dx.doi.org/ I0.I I6I/0I.STR.0000044I70.46643.5E

5 Libman RB,Wirkowski E,Alvir J et al. Conditions that mimic stroke in the emergency department. Implications for acute stroke trials. Arch Neurol 1995; 52: I I 19-22. http://dx.doi.org/10.1001/archneur 1995.00540350II3023
The presence or absence of particular clinical symptoms and signs are helpful in distinguishing stroke from a mimic. A recent systematic review ${ }^{R 2}$ found that patients with one or more of acute facial paralysis, arm drift or speech change increased the odds of stroke (odds ratio [OR] 5.5, 95\% Cl: 3.3-9.I). The absence of all three of these signs can be helpful in identifying patients who are unlikely to have had a stroke (OR of stroke $0.39,95 \% \mathrm{Cl}$ : 0.25-0.6I). These findings form the basis for the 'face, arm, speech time (FAST) test,' a rapid, simple clinical evaluation which can be applied by both medical professionals and members of the public to patients with suspected stroke.

We were unable to identify a search strategy with a high sensitivity for retrieving studies of differential diagnosis, we therefore may not have found all relevant published studies. The development of such a strategy would improve the quality of systematic reviews of the differential diagnoses of other diseases in future.

\section{CONCLUSIONS}

The best available estimate for the prior probability of stroke in patients with suspected stroke is $74 \%(95 \% \mathrm{Cl}$ : 66 to $83 \%$ ). A significant minority of patients seen by stroke services have not had a stroke, and arrangements need to be in place for their rapid review by those with an expertise in neurological disorders.

3 Robinson TG, Reid A, Haunton VJ et al. The face arm speech test: does it encourage rapid recognition of important stroke warning signs? Emerg Med J 2012; Epub ahead of print. http://dx.doi. org/I0.II36/emermed-20I2-20147I

6 Nor AM, Davis J, Sen B et al. The recognition of stroke in the emergency room (ROSIER) scale: development and validation of a stroke recognition instrument. Lancet Neurol 2005; 4:727-34. http://dx.doi.org/I0.10I6/SI474-4422(05)7020I-5

7 Ronning OM, Thommessen B. Nar hjerneslagdiagnosen er feil. Tidsskr Nor Laegeforen 2005; I 25: I655-7. [Norwegian].

8 Sibon I, Rouanet F, Meissner W et al. Use of the triage stroke panel in a neurologic emergency service. Am J Emerg Med 2009; 27:55862. http://dx.doi.org/I0.1016/j.ajem.2008.05.001

9 Whiteley W, Wardlaw J, Dennis M et al. Blood biomarkers for the diagnosis of acute cerebrovascular diseases: a prospective cohort study. Cerebrovasc Dis 201 I; 32:141-7. http://dx.doi.org//0.1I59/ 000328517

I0 Hopyan J, Ciarallo A, Dowlatshahi D et al. Certainty of stroke diagnosis: incremental benefit with CT perfusion over noncontrast CT and CT angiography. Radiology 2010; 255: I42-53. http://dx.doi. org/ I0.1 I48/radiol.09091021 
II Glickman SW, Phillips S, Anstrom KJ et al. Discriminative capacity of biomarkers for acute stroke in the emergency department. J Emerg Med 201I; 4l:333-39. http://dx.doi.org/l0.1016/j. jemermed.2010.02.025

12 Montaner J, Mendioroz M, Ribo $M$ et al. A panel of biomarkers including caspase-3 and d-dimer may differentiate acute stroke from stroke-mimicking conditions in the emergency department. Intern Med20 I I;270: I 66-74.http://dx.doi.org/I0. I I I I/j.I365-2796. 2010.02329.x

13 Vanni S, Polidori G, Pepe G et al. Use of biomarkers in triage of patients with suspected stroke. J Emerg Med 20I I; 40:499-505. http://dx.doi.org/10.1016/j.jemermed.2008.09.028

14 Karunaratne PM, Norris CA, Syme PD. Analysis of six months' referrals to a "one-stop" neurovascular clinic in a district general hospital: implications for purchasers of a stroke service. Health Bull (Edinb) 1999; 57:17-28.

15 Norris JW, Hachinski VC. Misdiagnosis of stroke. Lancet 1982; I:328-3I. http://dx.doi.org/I0.I0I6/S0 I40-6736(82)9I580-X

16 Vroomen PC, Buddingh MK, Luijckx GJ et al. The incidence of stroke mimics among stroke department admissions in relation to age group. J Stroke Cerebrovasc Dis 2008; 17:418-22. http://dx.doi. org/I0.1016/j.jstrokecerebrovasdis.2008.06.007

17 Moynihan B, Davis D, Pereira A et al. Delivering regional thrombolysis via a hub-and-spoke model. $J R$ Soc Med 2010; 103:363-9. http://dx.doi.org/I0.1258/jrsm.2010.090434

18 Foerch C, Niessner M, Back T et al. Diagnostic accuracy of plasma glial fibrillary acidic protein for differentiating intracerebral hemorrhage and cerebral ischemia in patients with symptoms of acute stroke. Clin Chem 20I I; 58:237-45. http://dx.doi.org/I0.I373/ clinchem.20II.I72676
19 Kidwell CS, Starkman S, Eckstein M et al. Identifying stroke in the field: prospective validation of the Los Angeles prehospital stroke screen (LAPSS). Stroke 2000; 3I:7I-6. http://dx.doi.org/I0.II6I/0I. STR.3I.I.7I

20 Nor AM, McAllister C, Louw SJ et al. Agreement between ambulance paramedic - and physician-recorded neurological signs with face arm speech test (FAST) in acute stroke patients. Stroke 2004; 35:I355-9. http://dx.doi.org/I0.II6I/0I.STR.0000I28529 63156.05

21 Broadley SA, Thompson PD. Time to hospital admission for acute stroke: an observational study. Med J Aust 2003; I78:329-3I.

22 Winkler DT, Fluri F, Fuhr P et al. Thrombolysis in stroke mimics: frequency, clinical characteristics, and outcome. Stroke 2009; 40: I 522-5. http://dx.doi.org/ I0. I I 6I/STROKEAHA. I08.530352

23 Cohen SN, Muthukumaran A, Gasser $\mathrm{H}$ et al. Symptom spread to contiguous body parts as a presentation of cerebral ischemia. Cerebrovasc Dis 2002; | 4:84-9.http://dx.doi.org/ I 0. I I 59/000064735

24 Kumwenda JJ, Mateyu G, Kampondeni S et al. Differential diagnosis of stroke in a setting of high HIV prevalence in Blantyre, Malawi. Stroke 2005; 36:960-4. http://dx.doi.org//0.II6I/0I.STR 0000162585.97216.ef

25 Rizos T, Ringleb PA, Huttner HB et al. Evolution of stroke diagnosis in the emergency room: a prospective observational study. Cerebrovasc Dis 2009; 28:448-53. http://dx.doi.org/I0.II59/ 000235989

\section{INVITATION TO SUBMIT PAPERS}

We would like to extend an invitation to all readers of The Journal of the Royal College of Physicians of Edinburgh to contribute original material, especially to the clinical section. The JRCPE is a peer-reviewed journal with a circulation of 8,000 . It is also available open access online. Its aim is to publish a range of clinical, educational and historical material of cross-specialty interest to the College's international membership.

The JRCPE is currently indexed in Medline, Embase, Google Scholar and the Directory of Open Access Journals. The editorial team is keen to continue to improve both the quality of content and its relevance to clinical practice for Fellows and Members. All papers are subject to peer review and our turnaround time for a decision averages only eight weeks.

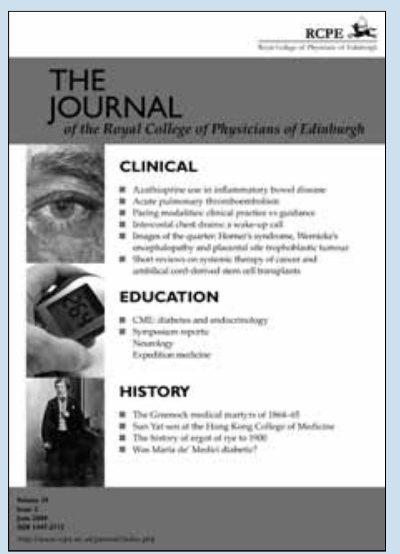

We would be pleased to consider submissions based on original clinical research, including pilot studies. The JRCPE is a particularly good forum for research performed by junior doctors under consultant supervision. We would also consider clinical audits where the 'loop has been closed' and a demonstrable clinical benefit has resulted.

For further information about submissions, please visit: http://www.rcpe.ac.uk/journal/contributers.php or e-mail editorial@rcpe.ac.uk. Thank you for your interest in the College's journal.

The editorial team,

The Journal of the Royal College of Physicians of Edinburgh 